\title{
Morfo-anatomía del ciclo de vida del helecho Pteridium aquilinum (Dennstaedtiaceae) en cultivo in vitro
}

\author{
Felipe de Jesús Eslava-Silva ${ }^{1}$, Karina Jiménez-Durán ${ }^{2}$, Manuel Jiménez Estrada ${ }^{1}$ \& \\ María Eugenia Muñiz Díaz de León ${ }^{3 *}$ \\ 1. Departamento de Productos Naturales, Instituto de Química, Universidad Nacional Autónoma de México, Ciudad \\ Universitaria, Alcaldía Coyoacán, Código Postal 04510, Ciudad de México, México; manuelj@unam.mx \\ 2. Laboratorio de Microscopía, Facultad de Química, Universidad Nacional Autónoma de México, Ciudad Universitaria, \\ Alcaldía Coyoacán, Código Postal 04510 Ciudad de México, México; jikary@unam.mx \\ 3. Departamento de Biología Comparada. Facultad de Ciencias, Universidad Nacional Autónoma de México, Ciudad \\ Universitaria, Alcaldía Coyoacán, Código Postal 04510, Ciudad de México, México; mathe18@yahoo.com.mx \\ * Correspondencia
}

Recibido 08-IV-2019. Corregido 02-IX-2019. Aceptado 25-X-2019.

\begin{abstract}
Morpho-anatomic of Pteridium aquilinum fern (Dennstaedtiaceae) life cycle in in vitro culture. Introduction: Pteridium aquilinum is a heliophilous fern widely distributed in Mexico. It is a pioneer species usually found within disturbed habitats with high ecological relevance because of its allelopathic properties, its resistance to fire and drought conditions. Objective: Provide an integrative description regarding P. aquilinum spores shape and ornamentation, and also on gametophyte morphogenesis, including the type of germination and the prothallic development (highlighting its morphology). Furthermore, the anatomy of young sporophyte grown under in vitro conditions was described. Methods: We used scanning electron microscopy and histological paraffin technique to describe the gametophytic and sporophytic phases. Results: The evaluation of the spores showed the presence of globular morphology and triletes with granulated ornamentation; while their germination was Vittaria-type, the prothallic development corresponded to the Adiantum-type. The antheridia were observed 13 days following to the sowing, whereas archegonia arose at day 17. The first leaf of the sporophyte appeared between days 60 and 70. At fourth month, the in vitro grown sporophyte showed the typical anatomy of the individuals of the species at this age, since it did not exhibit vitrification. The histological analysis of rhizome, the petiole base, first order rachis and lamina showed the three tissue systems well differentiated. The anatomical modifications observed in vitro, such as a non-polycyclic dictyostele and just one band sclerenchyma in the rhizome, may be attributed to the individuals age. Moreover, the stomata are present on the adaxial surface of lamina, corresponding to the anomocytic type. Although these stomata were developed under in vitro conditions, it is important to highlight that they are completely functional. Conclusions: Our work describes for the first time the morpho-anatomy of both the gametophytic and the sporophytic phases in the life cycle of $P$. aquilinum under in vitro conditions. Our results indicate that this method will allow deeper exploration of biological, physiological and ecological properties of the species.
\end{abstract}

Key words: anatomy, damage, fern, prothallial development, sphorophyte.

Eslava-Silva, F.J., Jiménez-Durán, K., Jiménez Estrada, M. \& Muñiz Díaz de León, M.E. (2019). Morfo-anatomía del ciclo de vida del helecho Pteridium aquilinum (Dennstaedtiaceae) en cultivo in vitro. Revista de Biología Tropical, 68(1), 12-22.

Pteridium aquilinum (L.) Kuhn es un helecho que pertenece a la familia Dennstaedtiaceae, conocido como helecho de potrero o helecho macho (Mora-Alvarado, 2003;
Rincón, Díaz, \& Gardner, 2016). Se encuentra ampliamente distribuido alrededor del mundo (Le Duc, Pakeman, \& Marrs, 2000). P. aquilinum posee amplias capacidades ecológicas: 
propagación subterránea, gran producción de esporas, alta resistencia al fuego y a la sequía, características que le permiten colonizar lugares inhóspitos, áreas perturbadas y actuar como planta pionera e invasora (Tinklin \& Bowling, 1969; Gliessman, 1978; Navar, Fernández, \& Del Amor, 1987; Moran, 1993; Dolling, 1999; Watrud et al., 2003; Riege \& Del Moral, 2004; Rámirez, Pérez, \& Orozco, 2007; Ramirez-Trejo, Pérez-García, Pérez-Salicrup, \& Orozco-Segovia, 2010). Esta planta produce metabolitos secundarios con una amplia acción biológica que le confieren propiedades alelopáticas, de defensa contra la herbívoria y antimicrobianas (Gliessman \& Muller, 1972, 1977; Gliessman, 1976; Schereiner, 1981; San Francisco \& Cooper-Driver, 1984; Navar et al., 1987; Dawra, Kurade, \& Sharma, 2002; Rasmussen, Kroghsbo, Frisvad, \& Hansen, 2003; Beniston \& Campo, 2005; Selvaraj, De Brito, \& Sahayaraj, 2005).

El ciclo de vida de esta especie, consta de dos fases heteromórficas, la esporofítica productora de esporas, que es la dominante y la gametofítica productora de gametos. Debido a que es difícil observar ambas fases del ciclo reproductivo de los helechos en el campo, se ha recurrido al cultivo in vitro como una herramienta para la observación de estas fases y su propagación bajo condiciones controladas y asépticas. (Morel \& Wetmore, 1951; Breznovits \& Mohay, 1985; Fernández \& Revi1la, 2003; Juárez-Orozco, Orozco-Segovia, Mendoza-Ruiz, \& Pérez-García, 2013). Con las técnicas in vitro se han estudiado varios aspectos de la biología de P. aquilinum. En la fase gametofítica (haploide) se ha descrito porcentaje de germinación, desarrollo protálico y formación del esporofito de poblaciones silvestres (Conway, 1949); inducción de esporofitos apogámicos bajo diferentes concentraciones de glucosa y sacarosa (Whittier \& Steeves, 1960; Whittier, 1964); el efecto de la luz en el patrón de división celular en las primeras etapas de desarrollo del gametofito, en específico de fase filamentosa a fase bidimensional (2D) (Sobota \& Partanen, 1966); para la observación de gametofitos maduros y de los anterozoides
(Elmore \& Adams, 1976); y la caracterización del transcriptoma de la fase gametofítica (Der, Barker, Wickett, \& Wolf, 2011). En la fase esporofítica (diploide) los estudios son pocos: se encuentra el trabajo de cultivo y desarrollo de las raíces in vitro (Partanen \& Partanen, 1963); y el de propagación de esporofitos para la obtención de ecdisteroides, metabolito utilizado para el control de plagas en cultivos (Macek \& Vaněk, 1994). A pesar de que se ha utilizado este helecho para diferentes objetivos usando el cultivo in vitro, no hay investigaciones que abarquen la descripción de su ciclo de vida completo. El objetivo de este estudio fue aportar información morfológica y anatómica de la fase gametofítica y esporofítica de $P$. aquilinum, utilizando la técnica "in vitro", dado que existen trabajos escasos sobre este tópico, usando microscopía fotónica y microscopía electrónica de barrido (MEB). Se describe el tipo y ornamentación de esporas, la germinación, el desarrollo protálico y la anatomía del esporofito (raíces, tallos y hojas).

\section{MATERIALES Y MÉTODOS}

Material biológico: Se recolectaron esporas de $P$. aquilinum en la localidad de "La Cantera" $\left(20^{\circ} 39^{\prime} 54.3 " \mathrm{~N} \& 98^{\circ} 39^{\prime} 56.2^{\prime \prime} \mathrm{W}\right.$, y altitud $2036 \mathrm{mnsm}$ ) ubicada en el Municipio de Zacualtipán, Hidalgo. Estas se desecaron naturalmente a temperatura ambiente, se tamizaron de acuerdo con el procedimiento de Muñiz, Pérez-García, Márquez-Guzmán y Mendoza-Ruiz (2008) y se mantuvieron a $4{ }^{\circ} \mathrm{C}$ hasta su siembra.

Cultivo in vitro: Durante la siembra in vitro, se tomaron $90 \mathrm{mg}$ de esporas, se lavaron con una solución al $0.3 \%$ de $\mathrm{NaClO}$ y se agitaron por dos minutos. Se recuperaron las esporas de la solución utilizando papel filtro. Posteriormente se realizaron cinco lavados con agua desionizada estéril, y finalmente se resuspendieron en $10 \mathrm{ml}$ de agua desionizada estéril. Se tomaron $250 \mu \mathrm{l}$ de la suspensión de esporas y se sembraron en cajas de Petri de $10 \mathrm{~cm}$ con $25 \mathrm{ml}$ de medio $1 / 2$ MS (Murashige \& Skoog, 
1962). Después de 15 días de la siembra los gametofitos fueron trasplantados a $1 / 2$ MS y regados dos veces por semana con $5 \mathrm{ml}$ de agua desionizada estéril, hasta la aparición de los esporofitos jóvenes y éstos se mantuvieron en condiciones in vitro hasta que tuvieron alrededor de cuatro meses.

Técnica para microscopia electrónica de barrido (MEB): Se tomaron muestras de la fase gametofítica en los diferentes estadios de desarrollo, así como del esporofito joven y fragmentos de $1 \times 1 \mathrm{~cm}$ de las hojas del esporofito de 60-70 días de edad. Con tres esporofitos de cuatro meses se realizaron cortes transversales de raíz, rizoma, base de pecíolo y raquis. El material obtenido se fijó en FAA (formaldehído, alcohol etílico, ácido acético glacial y agua; $1: 5: 0.5: 3.5)$ y se realizó la deshidratación gradual en etanoles $(30,50,70,85,96$ y 100 $\%$ ). Una vez que las muestras estuvieron en etanol al $100 \%$ se desecaron a punto crítico (Quorum Q150R ES). Las muestras desecadas de los gametofitos, esporofitos y las esporas, se montaron en porta muestras de aluminio sobre cinta de carbón hiperconductora, y fueron cubiertas con una solución de oro-paladio en spray (EMITECH k850). Las observaciones y las fotomicrografías se realizaron en un microscopio electrónico de barrido HITACHI SUI510 en formato TIFF y se editaron con Photoshop CS6 portátil.

Técnica histológica de inclusión en parafina para microscopia fotónica: Se realizaron cortes de $0.5 \mathrm{~cm}$ de longitud de raíz adventicia, rizoma, base del pecíolo, raquis y hoja, y se fijaron en FAA. Para la inclusión en parafina las muestras se deshidrataron en una serie gradual de etanol por $24 \mathrm{~h}(30,50,70,85$, 96 y $100 \%$ ), para la infiltración en parafina se pasaron por una mezcla de xilol-etanol (1:1), xilol, xilol: parafina $(2: 1,1: 1,1: 2)$ en cambios de $12 \mathrm{~h}$ cada uno, posteriormente se incluyeron en Paraplast ${ }^{\circledR}$ a $58-60{ }^{\circ} \mathrm{C}$. Una vez incluidas se realizaron cortes transversales de $8 \mu \mathrm{m}$ de grosor con un micrótomo semiautomático de rotación (Leica RM2165). Los cortes se desparafinaron y se tiñeron con la técnica de safranina-verde rápido en metilcelosolve y se montaron en portaobjetos con resina sintética de acuerdo con López, Márquez Guzmán y Murguía Sánchez (2005). Las microfotografías se tomaron con un microscopio con cámara incluida (Leica ICC50 E).

Para el tamaño de las esporas se midió eje polar y eje ecuatorial de 30 esporas. Para la descripción del tipo de germinación y desarrollo protálico se utilizó la terminología propuesta por Nayar y Kaur (1971), para corroborar los tiempos de desarrollo se realizaron tres réplicas independientes. La descripción anatómica de las estructuras del esporofito se realizó de acuerdo con Ogura (1972) y Talip et al. (2014), se midieron tres individuos y se reportaron promedio \pm desviación estándar.

\section{RESULTADOS}

Fase gametofítica: Las esporas son globosas, tetrahédricas, con lesura trilete y ornamentación granulada, de color marrón y aclorofílicas, su diámetro polar es $33.7 \pm 3.6$ $\mu \mathrm{m}$ y su diámetro ecuatorial es $37.4 \pm 3.4 \mu \mathrm{m}$, la vista proximal es triangular a subtriangularglobosa y la vista distal es globosa (Fig. 1A, Fig. 1B). La germinación es asincrónica y ocurre de tres a cinco días posteriores a la siembra (Fig. 1C) y corresponde al tipo Vittaria, donde la primera división es perpendicular al eje polar de la espora y da origen a la célula rizoidal. La segunda división es perpendicular a la primera y genera a la célula protálica (Fig. 1D). El desarrollo protálico se presenta sincrónico y corresponde al tipo Adiantum, el cual se caracteriza por la presencia de filamentos cortos de 4-6 células a partir del sexto día (Fig. 1E). El desarrollo de la fase bidimensional (2D) comienza a partir entre el séptimo y octavo día, originando gametófitos simétricos y desnudos, comienza a diferenciarse la célula meristemática por divisiones anticlinales en el ápice (Fig. 1F). A partir del día 11 se observa un talo de espatulado a cordiforme, desnudo, con alas desarrolladas y un meristemo apical en la zona de la muesca (Fig. 1G). Los gametófitos masculinos 

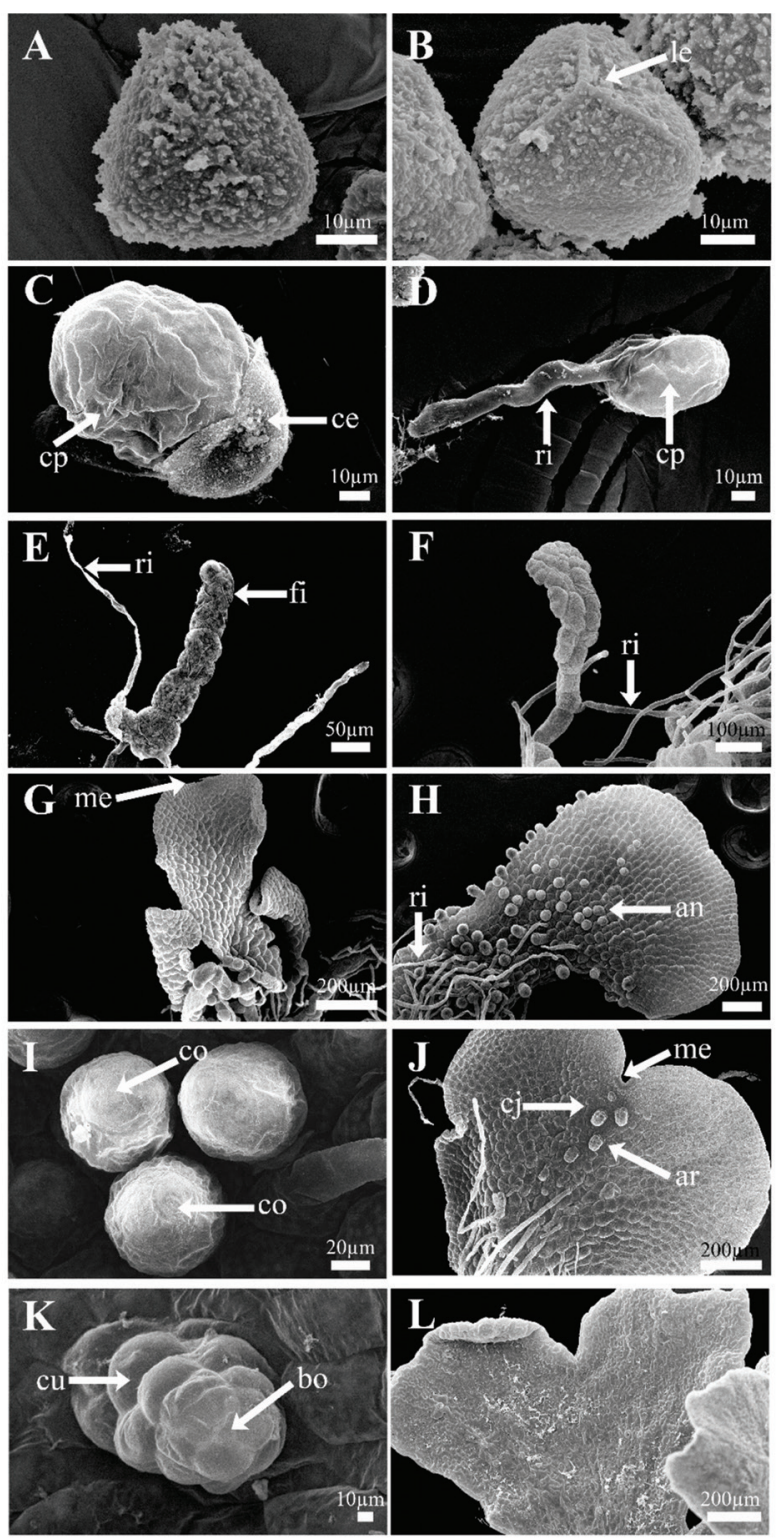

Fig. 1. Fase gametofítica de P. aquilinum. A. Espora en vista distal. B. Espora trilete en vista proximal. C y D. Germinación tipo Vittaria, 3-5 días. E. Fase filamentosa, 6 días. F. Inicios de la fase 2D, 7-8 días. G. Gametofitos espatulados, 11 días. H. Gametofitos con anteridios ventrales, 13 días. I. Detalle de anteridios. J. Gametofito con arquegonios, 17 días. K. Detalle de boca y cuello del arquegonio. L. Primera hoja del esporofito, 60-70 días. An $=$ anteridios, ar $=$ arquegonios, bo $=$ boca, $\mathrm{cb}=$ célula basal, $\mathrm{ce}=$ cubierta de la espora, $\mathrm{cj}=$ cojinete, $\mathrm{co}=$ célula opercular, $\mathrm{cp}=$ célula protálica, $\mathrm{cr}=$ célula rizoidal, $\mathrm{cu}=$ cuello, $\mathrm{fi}=$ filamento, $\mathrm{le}=$ lesura, $\mathrm{me}=$ meristemo $\mathrm{y} \mathrm{ri}=$ rizoide.

Fig. 1. Gametophytic generation from P. aquilinum. A. Spore distal face. B. Trilete spore proximal face. C y D. Vittaria-type germination, 3-5 days. E. Filamentous phase, 6 days. F. Beginning of 2D phase, 7-8 days. G. Gametophytes with spatulatedshape, 11 days. H. Gametophyte with mature antheridia, 13 days. I. Antheridia. J. Gametophyte with archegonia, 17 days. K. View of neck and mouth cells from archegonium. L. Sporophyte first leaf, 60-70 days. an = antheridia, ar = archegonia, bo $=$ mouth, $\mathrm{cb}=$ basal cell, $\mathrm{ce}=$ exospore, $\mathrm{cj}=$ cushion, $\mathrm{co}=$ opercular cell, $\mathrm{cp}=$ prothallic cell, $\mathrm{cr}=$ rhizoid cell, $\mathrm{cu}=\mathrm{neck}$, $\mathrm{fi}=$ filamentous, $\mathrm{le}=$ lesure, $\mathrm{me}=$ meristem and $\mathrm{ri}=$ rhizoid. 
se observan a partir de los trece días posteriores a la siembra lo que hace a esta especie protándrica. Los anteridios se encuentran en la superficie ventral de la lámina, ocupan 2/3 partes de la superficie del talo, entre los rizoides (Fig. $1 \mathrm{H})$, y presentan tres células: la célula basal, la célula media y la célula opercular (Fig. 1I). Los arquegonios se formaron a partir de los 17 días, en la superficie ventral del gametofito, cercanos a la muesca y como se observan orientados hacia adentro es indicación de autofecundación (Fig. 1J). Los cuellos tienen un largo de cuatro células y la boca de los arquegonios están formados por 4 células (Fig. 1K). La mayoría de los gametófitos son dioicos y presentan un claro dimorfismo sexual, los prótalos masculinos son espatulados y pequeños, los femeninos son de mayor tamaño, cordiformes y presentan a las amplias. Es posible observar gametofitos monoicos al día 21. La primera hoja de los esporofitos se observa entre 60 y 70 días posteriores a la siembra de las esporas, la primera hoja del esporofito es flabelada con venación dicotómica abierta (Fig. 1L).

Fase esporofítica: Los esporofitos de 60-70 días de edad presentan raíces adventicias, las cuales tienen un diámetro de $276.2 \pm$ $36 \mu \mathrm{m}$ y se aprecian los tres sistemas de tejidos bien desarrollados. La rizodermis es monoestratificada $16.4 \pm 6.2 \mu \mathrm{m}$ de grosor; el córtex $66.1 \pm 27.6 \mu \mathrm{m}$ de grosor y está constituido por 3-4 capas de células parenquimáticas de paredes delgadas, que conforme se acercan a la endodermis aumenta el grosor de las paredes; la endodermis está constituida por células alargadas con engrosamientos tangenciales de suberina en sus paredes; el periciclo consta de una o dos capas de células de grosor; el sistema vascular es del tipo monarca con un diámetro de $92.16 \pm 5.6 \mu \mathrm{m}$ con xilema exarco (Fig. 2A, Fig. 3A).

El rizoma tiene un diámetro ecuatorial de $2.13 \pm 0.23 \mathrm{~mm}$ y un diámetro meridional de $1.70 \pm 0.43 \mathrm{~mm}$ (Fig. 2B, Fig. 3B). En los extremos de la región ecuatorial se aprecian las lenticelas. La epidermis es monoestratificada $23.3 \pm 6.7 \mu \mathrm{m}$ de grosor. La hipodermis es pluriestratificada de 8-9 capas de células y de $64.4 \pm 56.7 \mu \mathrm{m}$ de grosor. El tipo de estela que presenta es dictiostela con 3-6 haces vasculares concéntricos (Fig. 3C). En el caso del xilema se observa el protoxilema maduro en la región periférica y el metaxilema aún está conformado por células vitalizadas debido a la corta edad de los individuos (Fig. 2C, Fig. 3D). La médula está constituida por células parenquimáticas y en proceso de diferenciación una banda central en forma de "C" de esclerénquima paralela al eje ecuatorial (Fig. 3C).

La base del pecíolo es de contorno cilíndrico a subtriangular y de $1.28 \pm 0.31 \mathrm{~mm}$ de grosor (Fig. 2D, Fig. 3F). En corte transversal la epidermis es monoestratificada compuesta por células isodiamétricas de $14.4 \pm 0.5 \mu \mathrm{m}$ de grosor (Fig. 3E). En posición subepidérmica se encuentra el tejido de sostén, con células isodiamétricas de paredes primarias o secundarias engrosadas de 1 a 5 capas de $36.1 \pm 18.7$ $\mu \mathrm{m}$ de grosor y parénquima de paredes delgadas de $850 \pm 191.6 \mu \mathrm{m}$ (Fig. 3F); el sistema vascular se encuentra en la porción central y está constituido por un haz vascular en un arreglo triangular (Fig. 3G).

El contorno adaxial del raquis es $3 / 4$ cilíndrico, el contorno de la cara abaxial es convexo en forma de "V" y de $867.8 \pm 143.7$ $\mu \mathrm{m}$ de ancho (Fig. 2E, Fig. 3H). En corte transversal la epidermis es simple conformada por células isodiamétricas de un grosor de $13.6 \pm$ $1.7 \mu \mathrm{m}$ (Fig. 3I). En la región subepidérmica hay un tejido de sostén con células lignificadas de $41.9 \pm 11.5 \mu \mathrm{m}$ de grosor, conformada por células de rectangulares a isodiamétricas, dispuestas en dos a cuatro capas y posteriormente se encuentra tejido parenquimático de paredes delgadas, el sistema vascular está constituido por cuatro haces vasculares de largo de 168.8 $\pm 55.6 \mu \mathrm{m}$ y ancho de $115.8 \pm 8.8 \mu \mathrm{m}$ en un arreglo radial (Fig. 3J).

La lámina es 1-pinnado-pinnatífida profusamente lobada (Fig. 2F). Las células epidérmicas de la cara adaxial de la lámina son sinuosas y de forma irregular, presenta tricomas aciculares pluricelulares de tres a cuatro células (Fig. $2 \mathrm{G})$. Las células epidérmicas de la cara abaxial 

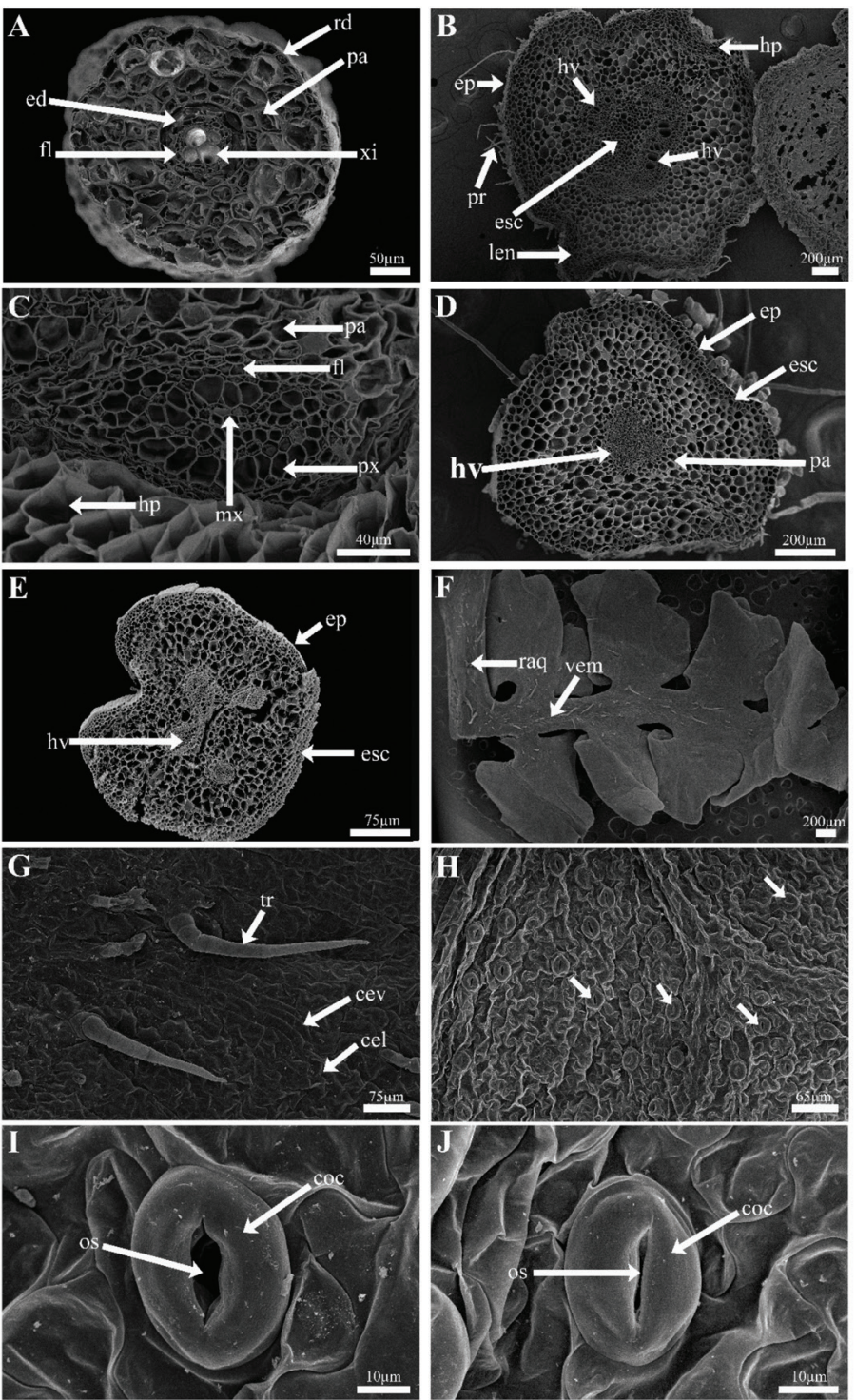

Fig. 2. Anatomía de la fase esporofítica de P. aquilinum. A. Corte transversal de raíz adventicia. B. Corte transversal de rizoma. C. Acercamiento a haz vascular del rizoma. D. Corte transversal de la base del peciolo. E. Corte transversal de raquis de primer orden. F. Pinna joven. G. Vista de la epidermis de la cara adaxial de la hoja. H. Vista de la epidermis de la cara abaxial de la hoja (flechas señalan a los estomas). I. Estoma anomocítico abierto. J. Estoma anomocítico cerrado. $\mathrm{Cel}=$ células epidérmicas del limbo de la hoja, cev = célula epidérmica asociadas al haz vascular, $\operatorname{coc}=$ células oclusivas, $\mathrm{e}=$ estomas, $\mathrm{ed}=$ endodermis, $\mathrm{ep}=$ epidermis, esc = esclerénquima, $\mathrm{fl}=$ floema, $\mathrm{hp}=$ hipodermis, $\mathrm{hv}=$ haz vascular, len $=$ lenticela, $\mathrm{mx}=$ metaxilema, $\mathrm{os}=$ ostiolo, $\mathrm{pa}=$ parénquima, $\mathrm{px}=$ protoxilema, $\mathrm{tr}=$ tricoma $\mathrm{rz}=$ rizodermis, vem $=\mathrm{vena}$ media y xi = xilema.

Fig. 2. Sporophytic generation anatomy from P. aquilinum. A. Adventitious root cross section. B. Rhizome Cross section of. C. Rhizome vascular bundle. D. Petiole base cross section. E. First order rachis cross section. F. Young pinna. G. View of adaxial face from leaf epidermis. H. View of abaxial face from leaf epidermis (arrows point the stomata). I. Anomocytic stoma open. J. Anomocytic stoma closed. cel = epidermal leaf limb cells, cev = epidermal cell associated with vascular bundle, $\mathrm{coc}=$ occlusive cells, $\mathrm{e}=$ stomata, $\mathrm{ed}=$ endodermis, $\mathrm{ep}=$ epidermis, esc $=$ sclerenchyma, $\mathrm{fl}=\mathrm{floem}, \mathrm{hp}=$ hipodermis, $\mathrm{hv}=$ vascular bundle, len $=$ lenticel, $\mathrm{mx}=$ metaxylem, os $=$ ostiolus, $\mathrm{pa}=$ parenchyma, $\mathrm{px}=$ protoxylem, $\mathrm{tr}=$ tricome $\mathrm{rz}=$ rhizodermis, $\mathrm{vem}=$ middle vein and $\mathrm{xi}=\mathrm{xylem}$. 

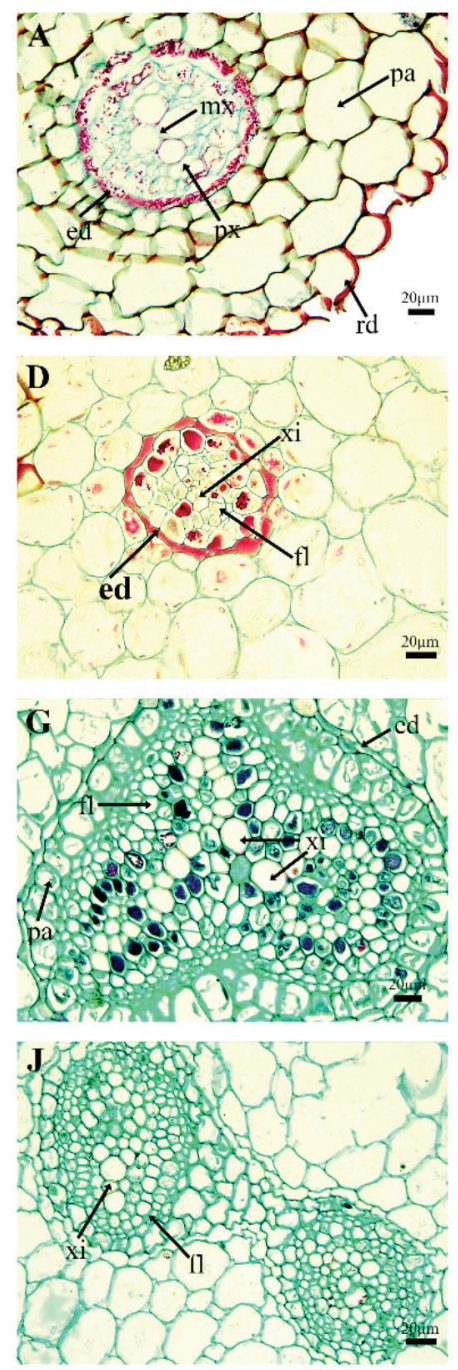
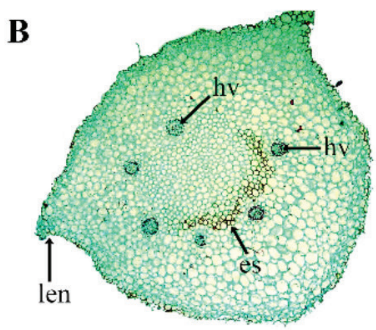

E

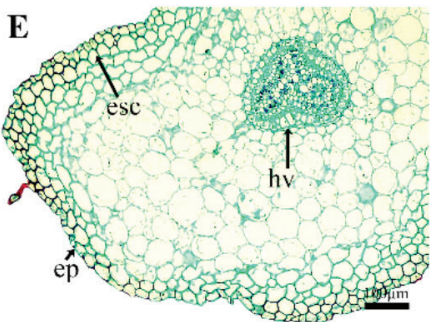

H

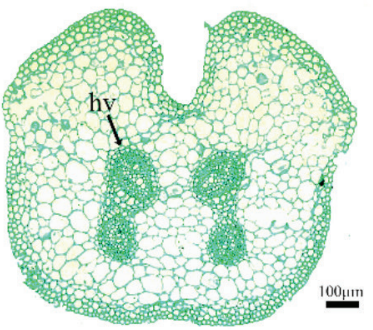

K

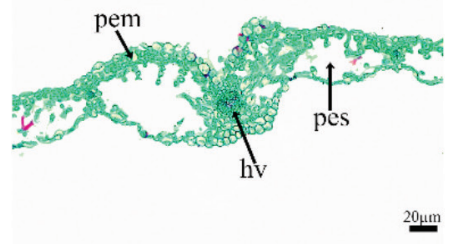

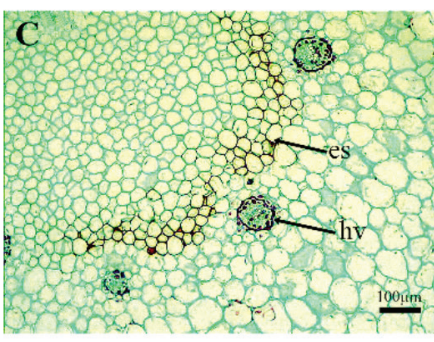

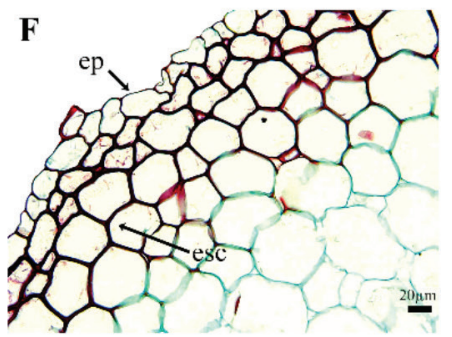

I
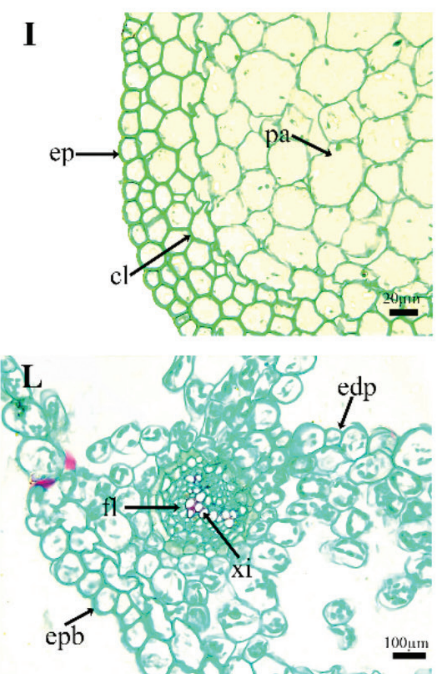

Fig. 3. Anatomía de la fase esporofítica de P. aquilinum con microscopía fotónica. A. Corte transversal de raíz adventicia. B. Corte transversal de rizoma. C. Acercamiento a la banda de esclerénquima. D. Acercamiento del haz vascular. E. Corte transversal de base de pecíolo. F. Acercamiento de epidermis y tejido de sostén de la base del pecíolo. G. Acercamiento del haz vascular de la base del pecíolo. H. Corte transversal de raquis de primer orden. I. Acercamiento de epidermis y tejido de sostén de raquis de primer orden. (J) Haz vascular de raquis de primer orden. K. Corte transversal de lámina. L. haz vascular primario de lámina. $\mathrm{Cl}=$ colénquima, ed = endodermis, esc $=$ esclerénquima, edp $=$ epidermis adaxial, epb $=$ epidermis abaxial, $\mathrm{fl}=$ floema, $\mathrm{hp}=$ hipodermis, $\mathrm{hv}=$ haz vascular, len=lenticela, $\mathrm{mx}=$ metaxilema, $\mathrm{pa}=$ parénquima, $\mathrm{px}=$ protoxilema, pem $=$ parénquima en empalizada, pes = parénquima esponjoso y $\mathrm{xi}=$ xilema.

Fig. 3. Sporophytic generation anatomy from P. aquilinum by photonic microscopy. A. Adventitious root cross section. B. Rhizome cross section. C. Sclerenchyma strand. D. Vascular bundle. E. Petiole base cross section. F. Epidermis and collenchyma from petiole base. G. Vascular bundle from petiole base. H. Cross section from first order rachis. I. Epidermis and support tissue from first order rachis. J. Vascular bundle from first order rachis. K. Leaf blade cross section. L. primary vascular bundle. $\mathrm{cl}=$ collenchyma, $\mathrm{ed}=$ endodermis, esc = sclerenchyma, edp = adaxial epidermis, epb = abaxial epidermis, $\mathrm{fl}=$ floem, $\mathrm{hp}=$ hipodermis, $\mathrm{hv}=$ vascular bundle, len $=$ lenticel, $\mathrm{mx}=$ metaxylem, $\mathrm{pa}=$ parenchyma, $\mathrm{px}=$ protoxylem, $\mathrm{pem}$ $=$ palisade parenchyma cells, pes $=$ spongy parenchyma cells and $x i=x y l e m$. 
son iguales a las de la cara adaxial, presenta estomas anomocíticos y funcionales de 35.8 $\pm 4 \mu \mathrm{m}$ largo y $36.5 \pm 5.5 \mu \mathrm{m}$ de ancho y la densidad estomática es de $72.5 \pm 19.8$ estomas $/ \mathrm{mm}^{2}$ (Fig. 2H, Fig. 2I y Fig. 2J). En corte transversal, la lámina presenta una epidermis monoestratificada en ambas caras, en la cara abaxial es de $20.3 \pm 3.8 \mu \mathrm{m}$ de grosor y en la cara abaxial es de $13 \pm 1.3 \mu \mathrm{m}$ de grosor (Fig. 3K). El mesófilo se encuentra diferenciado en empalizada $51 \pm 5 \mu \mathrm{m}$ de grosor orientado hacia la cara adaxial y esponjoso de $63.3 \pm 11.5$ $\mu \mathrm{m}$ de ancho, orientado hacia la cara opuesta, el haz vascular principal tiene un diámetro de $70 \pm 3.4 \mu \mathrm{m}$ (Fig. 3L).

\section{DISCUSIÓN}

La morfología de las esporas en $P$. aquilinum corresponde a los estudios previamente realizados por Tryon y Lugardon (1991), siendo la forma y la ornamentación la misma. En P. aquilinum la germinación es asincrónica, e inicia de 3-5 días posteriores a la siembra. El tiempo de germinación es semejante al reportado para otras especies de la familia, ya que en todas ocurre durante la primera semana después de la siembra (Campbell, 1936; Kaur, 1972; Zhang, Liu, \& Tan, 2008; Ramírez-Trejo, Pérez-García, Mendoza-Ruiz, Valdéz-Ávila, \& Espinosa-Matías, 2013; Martínez, Chambi, \& Avilés, 2014). Sin embargo, en P. aquilinum el tiempo de germinación es menor con respecto a las especies que conforman la familia, a excepción de $P$. caudatum en el que se reporta a los dos días posteriores a la siembra (Ramírez-Trejo et al., 2013). La germinación de P. aquilinum es del tipo Vittaria al igual que en las especies ya antes estudiadas como: Dennstaedtia scabra (Wall. ex Hook.) J. Sm. (Kaur, 1972), D. appendiculata var. elwesii (Wall. ex Hook.) J. Sm. (Kaur, 1972), D. globulifera (Poir.) Hieron. (Martínez et al., 2014), Histiopteris incisa (Thunb.) J. Sm. (Campell, 1936), H. poeppigii (Kunze) R. Rodr. (Martínez et al., 2014), Microlepia platyphylla (D. Don) J. Sm. (Zhang et al., 2008), M. strigosa (Thunb.) C. Presl (Zhang et al., 2008) y Pteridium caudatum
(L.) Maxon (Ramírez-Trejo et al., 2013), todas incluidas en la familia Dennstaedtiaceae de acuerdo a la Smith et al. (2006).

El desarrollo protálico es del tipo Adiantum al igual que el resto de las especies en la familia Dennstaedtiaceae (Campbell, 1936; Kaur, 1972; Zhang et al., 2008; Ramírez-Trejo et al., 2013; Martínez et al., 2014). Sin embargo, la morfogénesis de la fase sexual en esta especie, es más rápida que en el resto de los miembros de la familia, ya que a los 15 días en condiciones in vitro se observan gametofitos con anteridios y arquegonios. Esta condición no ha sido mencionada para otras especies en las que se ha estudiado la morfogénesis protálica, en los cuales los tiempos de desarrollo registrados son de uno a ocho meses (ReyesJaramillo, Peréz-García, \& Mendoza, 1995; Ramírez-Trejo et al., 2013).

En esta especie las primeras hojas del esporofito se observan entre los 60-70 días posteriores a la siembra, un tiempo muy parecido al observado en $P$. caudatum, en la que el tiempo desde la morfogénesis del gametofito hasta la formación del esporofito joven fue de 78 días (Ramírez-Trejo et al., 2013). El tiempo reducido de desarrollo protálico y la aparición del esporofito quizás sea una de las características que le permite a esta especie tener alta capacidad de ser pionera y colonizadora de sitios perturbados, y no solo, las características ecológicas adjudicadas al esporofito maduro, como la alelopatía entre otras (Moran, 1993; Ramírez et al., 2007; Ramírez-Trejo et al., 2010).

Las plantas vasculares en condiciones in vitro, debido a que se encuentran en un medio heterótrofo (medio suplementado con sacarosa) y condiciones de alta humedad pueden presentar varias anomalías anatómicas como: vitrificación, donde las células presentan paredes delgadas y una falta de diferenciación entre los sistemas de tejidos de los órganos; el mesófilo de las hojas sin diferenciación en empalizada y esponjoso, o solo la presencia de esponjoso; los estomas no funcionales o con mal formaciones en las células oclusivas (ausencia de ostíolo); y ausencia de cutícula (Reuther, 1987; 
Capellades, Fontarnau, Carulla, \& Debergh, 1990; Hazarika, 2006; Mohamed \& Alsadon, 2010; Gao, Xia, An, Xin, \& Liang, 2017). En $P$. aquilinum no se observa vitrificación en ningún órgano y se presentan los tres sistemas de tejidos bien diferenciados. La anatomía de las raíces adventicias es la típica descrita para esta especie (Kraehmer \& Baur, 2013), el rasgo particular observado en este estudio, es la ausencia de la capa de esclerénquima que normalmente rodea al haz vascular, ya que corresponde a la anatomía de los esporofitos de dos meses de edad. El rizoma típicamente presenta una dictiostela policíclica, con dos bandas de esclerénquima en la región ecuatorial, en este trabajo solo se observó un solo ciclo de haces vasculares y una banda de esclerénquima lo que concuerda con el desarrollo ontogenético para la especie (Ogura, 1972). La anatomía de la base del pecíolo debido a la corta edad de los individuos no presenta el sistema vascular en forma de águila bicéfala característico de la especie. Por otro lado, el raquis de primer orden presenta cuatro haces vasculares, rasgo reportado por primera vez. Las hojas son los órganos más afectados en las plantas in vitro (Capellades et al., 1990; Hazarika, 2006; Mohamed \& Alsadon, 2010), sin embargo, en P. aquilinum se observan los estomas anomocíticos funcionales en la cara adaxial, en corte transversal se diferencia bien el mesófilo en empalizada y el esponjoso y la cutícula es delgada.

La ausencia de daño en el desarrollo in vitro del gametofito y del esporofito de esta especie, podría significar, que, durante la aclimatación en condiciones de invernadero, la supervivencia de los individuos podrá ser mayor en individuos cultivados in vitro a partir de esporas.

Declaración de ética: los autores declaran que todos están de acuerdo con esta publicación y que han hecho aportes que justifican su autoría; que no hay conflicto de interés de ningún tipo; y que han cumplido con todos los requisitos y procedimientos éticos y legales pertinentes. Todas las fuentes de financiamiento se detallan plena y claramente en la sección de agradecimientos. El respectivo documento legal firmado se encuentra en los archivos de la revista.

\section{AGRADECIMIENTOS}

Se agradece a Conacyt y al Doctorado en Ciencias Biomédicas, UNAM, que otorgó una beca No. de Registro 47165 y dio el espacio de realizar su Doctorado al primer autor, respectivamente. Se agradece a Leonardo O. Alvarado Cárdenas por sus comentarios durante la elaboración del escrito.

\section{RESUMEN}

Introducción: Pteridium aquilinum es un helecho heliófilo ampliamente distribuido en México. Es una especie pionera que usualmente se encuentra en hábitats alterados y tiene gran relevancia ecológica por sus propiedades alelopáticas, su resistencia al fuego y a condiciones de sequía. Objetivo: realizar una descripción integral de la forma y ornamentación de las esporas de P. aquilinum, así como de la morfogénesis del gametofito, incluyendo el tipo de germinación y el desarrollo protálico (resaltando su morfología). Además, describir la anatomía del esporofito joven desarrollado en condiciones in vitro. Metodología: se utilizó microscopía electrónica de barrido y técnica histológica de parafina para la descripción de las fases del gametofito y esporofito. Resultados: Las esporas son globulares y el trilete tiene ornamentación granulada, mientras que su germinación fue de tipo Vittaria y el desarrollo protálico correspondió al tipo Adiantum. Los anteridios se observaron 13 días después de la siembra, mientras que los arquegonios surgieron al día 17. La primera hoja del esporofito apareció entre los días 60 y 70. Al cuarto mes, la fase esporofítica desarrollada in vitro mostró la anatomía típica de la especie a esta edad, dado que no presentó vitrificación. El análisis histológico del rizoma, la base del peciolo, el raquis de primer orden y la lámina mostraron los sistemas de tres tejidos bien diferenciados. Las modificaciones anatómicas observadas in vitro, como una dictiostela monocíclica y sólo una banda de esclerénquima en el rizoma, podrían atribuirse a la edad de los individuos. Por otra parte, los estomas están presentes en la superficie adaxial de la lámina, que corresponde al tipo anomocítico. Aunque estos estomas se formaron en condiciones in vitro, es importante resaltar que son completamente funcionales. Conclusiones: Nuestro trabajo describe por primera vez la morfo-anatomía de las fases gametofítica y esporofítica del ciclo de vida de P. aquilinum en condiciones in vitro. Nuestros resultados posiblemente permitan la exploración con mayor profundidad de las propiedades biológicas, fisiológicas y ecológicas de la especie. 
Palabras clave: anatomía, daño, desarrollo protálico, esporofito, helecho.

\section{REFERENCIAS}

Beniston, R., \& Campo, M. (2005). HPV-18 transformed cells fail to arrest in G1 in response to quercetin treatment. Virus Research, 109, 203-209.

Breznovits, A., \& Mohay, J. (1985). In vitro problems related to propagation of different fern species. In Symposium on In Vitro Problems Related to Mass Propagation of Horticultural Plants. Acta Horticulturae, 212, 427-432.

Campbell, E. O. (1936). The embryo and stelar development of Histiopteris incisa. Transactions of the Royal Society of New Zealand, 66, 1-11.

Capellades, M., Fontarnau, R., Carulla, C., \& Debergh, P. (1990). Environment influences anatomy of stomata and epidermal cells in tissue-cultured Rosa multiflora. Journal of the American Society for Horticultural Science, 115(1), 141-145.

Conway, E. (1949). XXII. - The Autecology of Bracken (Pteridium aquilinum (L.) Kuhn): The Germination of the Spore, and the Development of the Prothallus and the Young Sporophyte. Proceedings of the Royal Society of Edinburgh, Section B: Biological Sciences, 63(3), 325-343.

Dawra, R., Kurade, N., \& Sharma, O. (2002). Carcinogenicity of the fern Pteridium aquilinum collected from: Enzootic Bovine Haemeturia-Frre Hilly area in India. Current Science, 83, 1005-1009.

Der, J. P., Barker, M. S., Wickett, N. J., \& Wolf, P. G. (2011). De novo characterization of the gametophyte transcriptome in bracken fern, Pteridium aquilinum. BMC Genomics, 12(1), 99.

Dolling, A. (1999). The vegetative spread of Pteridium aquilinum in a hemiboreal forest invasion or revegetation? Forest Ecology and Management, 24, 177-1984.

Elmore, H., \& Adams, R. (1976). Scanning Electron Microscopic Observations on the Gametophyte and Sperm of the Bracken Fern, Pteridium aquilinum (L.) Kuhn. New Phytologist, 76(3), 519-522.

Fernández, H., \& Revilla, M. A. (2003). In vitro culture of ornamental ferns. Plant Cell, Tissue and Organ Culture, 73(1), 1-13.

Gao, H., Xia, X., An, L., Xin, X., \& Liang, Y. (2017). Reversion of hyperhydricity in pink (Dianthus chinensis L.) plantlets by $\mathrm{AgNO}_{3}$ and its associated mechanism during in vitro culture. Plant Science, $254,1-11$.

Gliessman, S. (1976). Allelopathy in a broad spectrum of environments as illustrated bay bracken. Botanical Journal of the Linnean Society, 73, 95-104.
Gliessman, S. (1978). The establishment of bracken following fire in tropical habitats. American Fern Journal, 68(2), 41-44.

Gliessman, S., \& Muller, C. (1972). The phytotoxic potential of bracken Pteridium aquilinum (L.) Kuhn. Madroño, 21, 299-304.

Gliessman, S., \& Muller, C. (1977). The allelopathic mechanisms of dominance in Bracken (Pteridium aquilinum) in Southern California. Journal of Chemical Ecology, 4(3), 337-362.

Hazarika, B. N. (2006). Morpho-physiological disorders in in vitro culture of plants. Scientia Horticulturae, 108(2), 105-120.

Juárez-Orozco, S., Orozco-Segovia, A., Mendoza-Ruiz, A., \& Pérez-García, B. (2013). Spore germination of eight homosporous ferns in a temperature gradient. South African Journal of Botany, 87, 112-117.

Kaur, S. (1972). Contributions to the morphology of Dennstaedtia. Proceedings of the Indian Academy of Sciences-Section B, 75(1), 32.

Kraehmer, H., \& Baur, P. (2013). Weed anatomy. USA: John Wiley \& Sons.

Le Duc, M. G., Pakeman, R. J., \& Marrs, R. H. (2000). Vegetation development on upland and marginal land treated with herbicide, for bracken (Pteridium aquilinum) control, in Great Britain. Journal of Environmental Management, 58, 147-160.

López Curto, M. D. L., Márquez Guzmán, J., \& Murguía Sánchez, G. (2005). Técnicas para el Estudio del Desarrollo en Angiospermas: Libro de Laboratorio. Ciudad de México, México: Universidad de Nacional Autónoma de México, Facultad de Ciencias.

Macek, T., \& Vaněk, T. (1994). Pteridium aquilinum (L.) Kuhn (bracken fern): in vitro culture and the production of ecdysteroids. In Y. P. S. Bajaj (Eds.), Medicinal and Aromatic Plants VI (pp. 299-315). Berlin, Heidelberg: Springer.

Martínez, O. G., Chambi, C. J., \& Avilés, Z. (2014). Gametophytic phase of two neotropical ferns, Dennstaedtia globulifera (Poir.) Hieron and Hypolepis poeppigii Mett. ex Maxon (Dennstaedtiaceae). Plant Systematics and Evolution, 300(5), 909-915.

Mohamed, M. H., \& Alsadon, A. A. (2010). Influence of ventilation and sucrose on growth and leaf anatomy of micropropagated potato plantlets. Scientia Horticulturae, 123(3), 295-300.

Mora-Alvarado, D. (2003). Evolución de algunos aspectos epidemiológicos y ecológicos del cáncer gástrico en Costa Rica. Revista Costarricense de Salud Pública, 12(21), 7-17.

Moran, R. C. (1993). Bracken, the poisoner. Fiddlehead Forum, 20(3), 18-20.

Morel, G., \& Wetmore, R. H. (1951). Fern callus tissue culture. American Journal of Botany, 38(2), 141-143. 
Muñiz, M. E., Pérez-García, B., Márquez-Guzmán, J., \& Mendoza-Ruiz, A. (2008). Developmental gametophyte morphology of seven species of Thelypteris subg. Cyclosorus (Thelypteridaceae). Micron, 39(8), 1351-1362.

Murashige, T., \& Skoog, F. (1962). A revised medium for rapid growth and bioassays with tobacco tissue culture. Physiology Plant, 15, 473-497.

Navar, V., Fernández, E., \& Del Amor, S. (1987). Allelopathic effects of green fronds of Pteridium aquilinum on cultivated plants, weeds, phytopathogenic fungi and bacteria. Agriculture, Ecosystem and Environment, 18, 357-379.

Nayar, B. K., \& Kaur, S. (1971). Gametophytes of homosporous ferns. The Botanical Review, 37(3), 295.

Ogura, Y. (1972). Comparative anatomy of vegetative organs of the pteridophytes. Berlin, Alemania: Gebrüder Borntraeger.

Partanen, J. N., \& Partanen, C. R. (1963). Observations on the culture of roots of the bracken fern. Canadian Journal of Botany, 41(12), 1657-1661.

Ramírez-Trejo, M., Pérez-García, B., Mendoza-Ruiz, A., Valdéz-Ávila, R., \& Espinosa-Matías, S. (2013). Observations of the spore, gametophyte and young sporophyte of Pteridium caudatum (L.) Maxon using scanning electron microscopy. Micron, 45, 37-44.

Ramírez, M., Pérez, B., \& Orozco, A. D. (2007). Helechos invasores y sucesión secundaria post-fuego. Ciencias, $85,18-25$.

Ramírez-Trejo, M. D. R. R., Pérez-García, B., PérezSalicrup, D. R., \& Orozco-Segovia, A. (2010). Effect of fire on the germination of spores of Pteridium caudatum, an invasive fern. Journal of Tropical Ecology, 26(4), 457-465.

Rasmussen, L., Kroghsbo, S., Frisvad, J., \& Hansen, H. (2003). Occurrence of the carcinogenic Bracken constituent ptaquiloside in fronds, topsoils and organic soil layers in Denmark. Chemosphere, 51, 117-127.

Reuther, G. (1987). Comparative anatomical and physiological studies with ornamental plants under in vitro and greenhouse conditions. In International Symposium on Propagation of Ornamental Plants. Acta Horticulturae, 226, 91-98.

Reyes-Jaramillo, I., Peréz-García, B., \& Mendoza, A. (1995). Plantas miniaturas de la naturaleza: gametofitos de helechos. Contactos, 12, 5-10.

Riege, D. A., \& Del Moral, R. (2004). Differential tree colonization of old fields in a temperate rain forest. The American Midland Naturalist, 151(2), 251-265.

Rincón, D. F., Díaz, G. J., \& Gardner, D. R. (2016). Detección de ptaquilósido en diferentes estados fenológicos de "helecho macho" (Pteridium aquilinum) y análisis de muestras de leche en granjas con hematuria en Tolima, Colombia. Revista CES Medicina Veterinaria y Zootecnia, 11(1), 72-77.
San Francisco, M., \& Cooper-Driver, G. (1984). Antimicrobial activity of phenolic acids in Pteridium aquilinum. American Fern Journal, 74(3), 87-95.

Schereiner, I. (1981). Cyanogenesis and the herbivorous insects of bracken fern (Pteridium aquilinum) (Ph.D. Thesis). Cornell University, Ithaca, NY, USA.

Selvaraj, P., De Brito, J., \& Sahayaraj, A. (2005). Phytoecdisone of Pteridium aquilinum (L.) Kuhn (Dennstaedticaceae) and its pesticidal property on two major pest. Archives of Phytopatology and Plant Protection, 38(2), 99-105.

Smith, A. R., Pryer, K. M., Schuettpelz, E., Korall, P., Schneider, H., \& Wolf, P. G. (2006). A classification for extant ferns. Taxon, 55(3), 705-731.

Sobota, A. E., \& Partanen, C. R. (1966). The growth and division of cells in relation to morphogenesis in fern gametophytes: I. Photomorphogenetic studies in Pteridium aquilinum. Canadian Journal of Botany, 44(4), 497-506.

Talip, N., Amirul-Aiman, A. J., Jaman, R., Nor-Fairuz, A. R., Maideen, H. M. K., Mohammed, A. D. H., \& Ruzi, A. R. (2014). Systematic significance of stipe anatomy in peninsular Malaysian Blechnum 1. (blechnaceae) species. Malaysian Applied Biology, 43(2), 119-128.

Tinklin, R., \& Bowling, D. (1969). The Water Relations of Bracken: A Preliminary Study. Journal of Ecology, 57(3), 669-671.

Tryon, A., \& Lugardon, B. (1991). Spores of the Pteridophyta: Surface, Wall Structure and Diversity Based on Electron Microscope Studies. New York: Springer-Verlag.

Watrud, L., Maggard, S., Shiroyama, T., Coleman, C., Johnson, M., Donegan, K., ... Lee, E. (2003). Bracken (Pteridium aquilinum L.) frond biomass and rhizosphere microbial community characteristics are correlated to edaphic factors. Plant and Soil, 249(2), 359-371.

Whittier, D. P. (1964). The influence of cultural conditions on the induction of apogamy in Pteridium gametophytes. American Journal of Botany, 51(7), 730-736.

Whittier, D. P., \& Steeves, T. A. (1960). The induction of apogamy in the bracken fern. Canadian Journal of Botany, 38(6), 925-930.

Zhang, L. X., Liu, B. D., \& Tan, L. Y. (2008). Gametophyte development of Microlepia strigosa and $M$. platyphylla (Dennstaedtiaceae). Journal of Tropical and Subtropical Botany, 3, 014. 